\title{
Erratum
}

In the article "Influence of Fatty Liver on Plasma Small, Dense LDL- Cholesterol in Subjects with and without Metabolic Syndrome" by Ikumi Sugino, et al., which appeared in JAT 2011, 18: 1-7, Running title is incorrect. below.

The editorial staff apologized to the authors and all readers. The correct text is presented with corresponding

Original Article

\section{Influence of Fatty Liver on Plasma Small, Dense LDL- Cholesterol in Subjects with and without Metabolic Syndrome}

\author{
False
}

Metabolic Syndrome and Fatty Liver in Small, Dense LDL

\section{Correct}

Fatty Liver and Small, Dense LDL in Metabolic Syndrome 